\title{
Avaliação da lipase extracelular de Pseudomonas cepacia para purificação em sistema bifásico aquoso
}

\author{
Evaluation of an extrecellular lipase from Pseudomonas cepacia \\ for purification in aqueous two-phase system
}

\author{
Giovana Silva PADILHA ${ }^{1}$, Juliana Ferrari FERREIRA ${ }^{1}$, Gabriel Luis CASTIGLIONI ${ }^{2}$, \\ Ranulfo Monte ALEGRE², Elias Basile TAMBOURGI ${ }^{1 *}$
}

\begin{abstract}
Resumo
O presente trabalho teve como objetivo a produção de lipase a partir de Pseudomona cepacia por fermentação líquida em biorreator do tipo Bioflo III. As fermentações foram conduzidas a $150 \mathrm{rpm}$ durante 96 horas a $30^{\circ} \mathrm{C}$. Analisou-se a atividade enzimática em diferentes condições de temperatura $\left(20\right.$ a $\left.50^{\circ} \mathrm{C}\right)$ e $\mathrm{pH}(3,0$ a 11,0$)$, e obtiveram-se $37^{\circ} \mathrm{C}$ e 8,0 , as condições ótimas, respectivamente. Para avaliar a estabilidade térmica, a enzima foi incubada em temperaturas de 40,50 e $60^{\circ} \mathrm{C}$ durante 120 minutos. Em uma segunda etapa, foram realizados experimentos preliminares para verificar as condições adequadas de partição da enzima, bem como sua estabilidade e condições ótimas de hidrólise frente às modificações de temperatura e pH. Foram preparadas soluções de PEG 1500, 4000 e 6000 a 50\% p/p e soluções tampão fosfato de pHs 6, 7 e 8. Foi feita a caracterização de um sistema bifásico aquoso (SBA) a partir da preparação de soluções estoques de PEG com massas molares de 1500, 4000 e 6000 (50\% w/w) e tampão fosfato pH 6,7 e 8,0 (20\% w/w de KH2PO4/K2HPO4). Esta caracterização do SBA posteriormente poderá ser utilizada para partição de lipases, bem como de biomoléculas que estejam dentro dessa faixa de $\mathrm{pH}$.
\end{abstract}

Palavras-chave: Pseudomonas cepacia; lípase; purificação.

\begin{abstract}
In this work, Pseudomonas cepacia was used for fermentation in bioreactor Bioflo III at $150 \mathrm{rpm}$, at $30^{\circ} \mathrm{C}$ to 96 hours. Fermentation was conducted at $150 \mathrm{rpm}$ for 96 hours in $30^{\circ} \mathrm{C}$. We analyzed the enzyme activity under different conditions of temperature $\left(20\right.$ to $\left.50^{\circ} \mathrm{C}\right)$ and $\mathrm{pH}$ (3.0 to 11.0). The optimum activity values obtained were $37^{\circ} \mathrm{C}$ and 8.0 , respectively. To evaluate thermal stability, the enzyme was incubated in temperatures of 40,50 and $60^{\circ} \mathrm{C}$ for 120 minutes. Preliminary experiments were carried out to verify the appropriate conditions that should be used after the enzyme partition. Some tests were performed to determine some optimal conditions of lipase, including temperature and $\mathrm{pH}$ and tests of thermal stability using temperatures of 40,50 , and $60^{\circ} \mathrm{C}$. Next, the characterization of aqueous two-phase systems (ATPS) with PEG molar weight of 1500, 4000, and 6000 and phosphate varying pH 6 to 8 was made. Stock solutions of PEG 1500,4000 and 6000 $(50 \% \mathrm{w} / \mathrm{w})$ and phosphate $(20 \% \mathrm{w} / \mathrm{w} \mathrm{KH} 2 \mathrm{PO} 4 / \mathrm{K} 2 \mathrm{HPO} 4)$ were prepared at the appropriate $\mathrm{pH}$. This study on the characterization of the ATPS can be used for posterior partition of lipase, as well as of biological products within this $\mathrm{pH}$ range.

Keywords: Pseudomonas cepacia; lipase; purification.
\end{abstract}

\section{Introdução}

As lipases (triglicerol acil-hidrolases E.C. 3.1.1.3) são enzimas responsáveis pela catálise de reações que envolvem hidrólise e síntese de éster a partir do glicerol e ácidos graxos de cadeias longas. Tais reações fazem com que estas enzimas sejam consideradas como um importante grupo de biocatalisadores (CASTRO; ANDERSON, 1995). As lipases podem ser obtidas a partir de diferentes fontes, dentre elas plantas, animais, fungos e bactérias. Do ponto de vista econômico e industrial, as lipases microbianas apresentam vantagens devido à facilidade de obtenção por processos fermentativos (BORGSTRÖM; BROCKMAN, 1984; HASAN; SHAH; HAMEED, 2006). Dentre os microrganismos produtores de lipase, destacam-se os fungos dos gêneros Rhizopus, Aspergillus e Mucor, bactérias do gênero Pseudomonas e leveduras do gênero Candida (KORDEL et al., 1991).

Os avanços biotecnológicos na produção industrial das lipases vêm proporcionando sua aplicação nos diferentes segmentos industriais e biotecnológicos. Embora ainda hoje a maior aplicação industrial destas enzimas seja na formulação de detergentes (KIRK; BORCHERT; FUGLSANG, 2002), sua capacidade hidrolítica faz com que algumas indústrias de papel e celulose utilizem-na para a remoção de material hidrofóbico da madeira, indesejáveis na manufatura do papel

Recebido para publicação em $7 / 7 / 2008$

Aceito para publicação em 31/10/2009 (003645)

${ }^{1}$ Departamento de Engenharia de Sistemas Químicos, Faculdade de Engenharia Química, Universidade Estadual de Campinas - UNICAMP, Av. Albert Einstein, 500, Cidade Universitária, CP 6066, CEP 13083-970, Campinas - SP, Brasil, E-mail: eliastam@feq.unicamp.br

2 Departamento de Engenharia de Alimentos, Faculdade de Engenharia de Alimentos, Universidade Estadual de Campinas - UNICAMP, Rua Monteiro Lobato, 80, Cidade Universitária, CP 6121, CEP 13083-862, Campinas - SP, Brasil

${ }^{*}$ A quem a correspondência deve ser enviada 
(JAEGER; EGGERT, 2002). As lipases também são utilizadas no tratamento de efluentes de indústrias, restaurantes e residências. Outra aplicação das lipases tem sido na hidrólise seletiva de triacilgliceróis com a consequente liberação de ácidos graxos, atuando como flavorizantes em alguns produtos lácteos, bebidas alcoólicas, achocolatados e sobremesas (HASAN; SHAH; HAMEED, 2006; PANDEY et al., 1999; JAEGER; EGGERT, 2002).

Devido à diversidade de aplicações das lipases, vários estudos relacionados às suas propriedades vêm sendo realizados com o intuito de determinar o perfil de atividade catalítica em diferentes condições de reação (PANDEY et al., 1999). A temperatura e o pH são alguns dos fatores de extrema importância nas reações catalisadas pelas lipases. Tais condições podem favorecer a velocidade de reação por um determinado tempo (SHARMA et al., 2002).

Com o crescimento do mercado, alguns segmentos industriais exigem uma etapa de purificação de enzimas para aumentar seu grau de pureza. As lipases microbianas são normalmente purificadas utilizando métodos convencionais, porém podem apresentar a desvantagem do baixo rendimento final. Devido a esta observação, alguns métodos de separação são mais indicados para a separação de produtos biotecnológicos. A partição de biomoléculas em sistemas bifásicos aquosos (SBA) é um dos métodos que vem sendo utilizado de forma eficiente na extração de proteínas, enzimas e ácidos nucleicos (BRADOO; SAXENA; GUPTA, 1999; SHARMA et al., 2002; PESSOA JR.; KILIKIAN, 2005).

Os SBAs podem ser formados por uma solução aquosa de dois polímeros hidrofílicos ou pela adição de um polímero e um sal. A separação das fases ocorre acima das concentrações termodinâmicas críticas desses componentes. Quando essas concentrações excedem determinado valor, há a formação das duas fases aquosas, formando um meio capaz de manter a atividade biológica de macromoléculas, para posterior partição (ALBERTSSON, 1971; CABEZAS, 1996; PESSOA JR.; KILIKIAN, 2005).

A fim de representar os dados termodinâmicos de um SBA como composições das fases e concentrações das misturas polímero-polímero ou polímero-sal, necessárias para a separação das fases, faz-se uso de um diagrama de equilíbrio de fases. A determinação do diagrama de equilíbrio de fases é a primeira etapa para caracterizar os sistemas bifásicos aquosos que contém informações de concentrações de PEG e sal necessárias à formação das fases, composição das fases em equilíbrio e previsão qualitativa da partição de moléculas (BADR; CABEZAS, 1996; ZUÑIGA et al., 2003). Neste trabalho, a escolha do PEG se deve à formação eficiente de fases em meio aquoso sem provocar a diminuição da atividade funcional de biomoléculas. Outra vantagem do uso do PEG é devido a sua biodegradabilidade e não toxicidade (HARRIS, 1992). Embora existam diversos sais que formem duas fases com o PEG, a escolha do sal fosfato de potássio foi baseada no seu baixo custo e alto coeficiente de partição de biomoléculas em relação a outros sais (ALBERTSSON, 1971). Em um diagrama de fase, também são representadas as linhas de amarração ou tie-lines.
Estas linhas ligam pontos no diagrama, capaz de representar a composição das duas fases em equilíbrio. Qualquer ponto sobre a linha de amarração fornecerá fases superiores e inferiores (fase de topo e fase de fundo) com a mesma composição final, porém com diferentes relações de volumes entre as fases (DA SILVA; LOH, 2006).

Pastore, Costa e Koblitz (2003), em estudos de produção e purificação de lipase utilizando Rizopus sp. por fermentação em meio contendo azeite de oliva, obtiveram fator de purificação próximo de $5 \%$ e recuperação da atividade abaixo dos $3 \%$. Os sistemas de purificação empregados no processo foram fracionamento com sulfato de amônio e cromatografia em resina SEPHADEX. Estudos realizados por Sharma et al. (2002) mostram que a purificação de lipase de Bacilus sp. RSJ.1 foi possível empregando etapas de centrifugação, precipitação com sulfato de amônio, diálise, cromatografia de troca iônica e filtração em gel, obtendo fator de purificação acima dos $200 \%$ e recuperação da atividade da enzima inferior a $20 \%$. Trabalhos semelhantes de precipitação e cromatografia também foram estudados por Kordel et al. (1991) e Lin et al. (2003), utilizando lipase de Pseudomonas sp. e Pseudomonas pseudoalcaligenes F-111, respectivamente.

Estudos de purificação de lipases neutras e ácidas de Bacillus stearothermophilus SB-1 com SBA PEG/ fosfato foram realizados por Bradoo, Saxena e Gupta (1999), utilizando mistura de sal fosfato e $\mathrm{NaCl}$. Os resultados encontrados pelos pesquisadores mostram o bom potencial deste método (5,27 e 15,25 para as lipases ácida e neutra, respectivamente). Tendo em vista estas observações, o presente trabalho teve como objetivo produzir e determinar as condições ótimas de hidrólise da lipase de Pseudomonas cepacia e caracterizar o sistema bifásico aquoso PEG/fosfato para posterior purificação desta enzima.

\section{Material e métodos}

\subsection{Material}

\section{Microrganismo}

Foi utilizada a cepa de Pseudomonas cepacia, obtida da Fundação André Tosello, mantida em tubos de ensaio a $4{ }^{\circ} \mathrm{C}$, no ágar nutriente.

\section{Equipamentos}

Para garantir condições estéreis de crescimento dos microrganismos, dos meios sólidos de propagação, do inóculo e de produção, utilizou-se a autoclave a $121^{\circ} \mathrm{C}$ durante 15 minutos. $\mathrm{O}$ agitador orbital utilizado para a análise lipolítica e caracterização enzimática foi o TE-421 da Tecnal e, para produção enzimática, usou-se o reator BIOFLO III da New Brunswick Scientific.

\section{Reagentes}

Todos os reagentes utilizados foram de grau de pureza analítico. A acetona, álcool etílico, fosfato monobásico de sódio, fosfato dibásico de sódio, fosfato monobásico de potássio, fosfato 
dibásico de fosfato, sulfato de magnésio, bicarbonato de sódio, carbonato de sódio, hidróxido de sódio, ácido acético, acetato de sódio e o polietileno glicol com massa molar de 1500, 4000 e 6000 foram adquiridos pela Synth (Diadema-SP). A goma arábica, ágar-ágar, extrato de levedura e peptona bacteriológica foram obtidos da Oxoid (Londres, UK). Os óleos de soja (Liza) e azeite de oliva (Gallo) foram obtidos no comércio local com acidez máxima declarada pelos fabricantes de 0,3 e 0,5\%, respectivamente. A albumina de soro bovino (BSA) com $98 \%$ de grau de pureza foi adquirida da Sigma (EUA).

\subsection{Métodos}

\section{Preparo do inóculo e sistema fermentativo}

O microrganismo foi transferido a partir de tubos de ensaio com ágar inclinado para Erlenmeyers de $125 \mathrm{~mL}$ contendo extrato de levedura ( 3 g.L. $\left.\mathrm{L}^{-1}\right)$, peptona $\left(3 \mathrm{~g} . \mathrm{L}^{-1}\right), \mathrm{K}_{2} \mathrm{PO}_{4}$ (4 g.L.-1) e $\mathrm{MgSO}_{4}(0,2$ g.L.-1 $)$ e $3 \%$ de óleo de soja. A adaptação do microrganismo foi realizada durante 48 horas a $30{ }^{\circ} \mathrm{C} \mathrm{e}$ $150 \mathrm{rpm}$. Após adaptação do microrganismo, o inóculo foi transferido para biorreator tipo Bioflo III (com volume útil de $5000 \mathrm{~mL}$ contendo $3000 \mathrm{~mL}$ de meio). $\mathrm{O}$ ar foi fornecido por compressor, esterilizado por filtro de lã de vidro e a vazão foi controlada por meio de rotâmetros. O meio de cultivo estudado por Castiglioni e Monte Alegre (2007) apresentou as mesmas concentrações preparadas para o inóculo, porém com $6 \%(\mathrm{v} / \mathrm{v})$ de óleo de soja para induzir a produção da lipase. A fermentação foi conduzida a $30^{\circ} \mathrm{C}, \mathrm{pH} 7,0$, aeração de 1,5 vvm e agitação de $150 \mathrm{rpm}$ durante 96 horas.

\section{Obtenção do extrato enzimático}

Após as 96 horas de fermentação, o meio foi coletado e centrifugado à temperatura ambiente durante 10 minutos a 2016 g. O sobrenadante foi utilizado como extrato enzimático, uma vez que a Pseudomonas cepacia produz lipase extracelular (KORDEL et al., 1991).

\section{Determinação da atividade lipolítica}

A atividade da lipase foi determinada segundo a metodologia descrita por Macedo, Park e Pastore (1997). As características da enzima foram estudadas com o extrato bruto. Para a avaliação da atividade da lipase em diferentes condições de temperatura, foi utilizado agitador orbital a $20,25,30,35,37,40,45$ e $50^{\circ} \mathrm{C}$. Já para a determinação da estabilidade térmica foi utilizado paralelamente sistema em banho-maria a 40,50 e $60^{\circ} \mathrm{C}$, com coletas de amostras em intervalos de 15, 30, 60, 90 e 120 minutos. $\mathrm{O}$ pH ótimo de atuação da lipase foi determinado com tampão citrato (pHs de 3,0 a 5,0), tampão fosfato (pHs de 6,0 a 8,0) e tampão carbonato-bicarbonato (pHs de 9,0 a 11,0).

\section{Determinação do teor de proteínas totais}

A concentração de proteínas no extrato enzimático foi determinada segundo a metodologia descrita por Bradford (1976), tendo como padrão a albumina de soro bovino.

\section{Determinação do diagrama de equilíbrio de fases}

A construção dos diagramas de fases foi realizada utilizando diferentes composições de PEG e sal, segundo a metodologia descrita por Albertsson (1971). Solução de fosfato a $20 \%$ foi adicionada lentamente à temperatura ambiente em solução de PEG até atingir a turbidez. $\mathrm{O}$ mesmo procedimento foi realizado para obtenção dos resultados com alta concentração de PEG em soluções a $50 \%$. As diferentes composições permitiram a construção da curva binodal do sistema para cada condição de processo.

\section{Determinação das linhas de amarração}

Os pontos que deram origem às linhas de amarração (tie-lines) foram obtidos para cada condição de $\mathrm{pH}$ a partir da massa de solução concentrada de PEG $(50 \% \mathrm{w} / \mathrm{w})$ e sal fosfato $(20 \% \mathrm{w} / \mathrm{w})$, em que observou-se a formação das fases superior (fase topo) e inferior (fase de fundo) de igual volume. A determinação das composições das linhas de amarração foi feita utilizando-se o método dos mínimos quadrados.

\section{Resultados e discussão}

\subsection{Caracterização bioquímica da enzima}

Na Figura 1, são apresentados os resultados da atividade lipolítica para essas diferentes condições de temperatura utilizadas na determinação da temperatura ótima de reação.

Com base nos resultados, observou-se que a $37^{\circ} \mathrm{C}$ a atividade da lipase apresentou valor máximo $\left(1,85 \mathrm{U} \cdot \mathrm{mL}^{-1}\right)$, correspondendo a uma atividade específica de $29,30 \mathrm{U}_{\mathrm{mg}}{ }^{-1}$. A maior variação encontrada para os valores de atividade foi de $17 \%$ (entre 20 e $37^{\circ} \mathrm{C}$ ). Algumas enzimas podem perder sua atividade com pequenas variações na temperatura, pois a mudança em sua conformação faz com que seu sítio ativo perca a especificidade de reagir com o substrato. Pela variação dos resultados da atividade lipolítica é provável que a lipase produzida por Pseudomonas cepacia tenha um ou dois sítios ativos, pois, dependendo da mudança conformacional da molécula, a enzima não perde totalmente sua atividade. A temperatura ótima de reação da lipase de Pseudomonas cepacia encontrada neste trabalho foi a mesma encontrada por

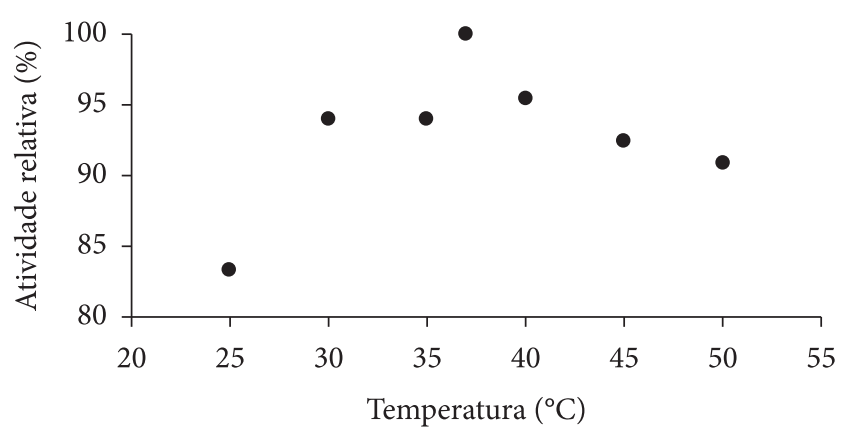

Figura 1. Atividade relativa de lipase produzida por Pseudomonas cepacia utilizando diferentes condições de temperatura. 
Pencreac'h e Barrati (1996). Valores semelhantes $\left(40^{\circ} \mathrm{C}\right)$ foram encontrados por Makhzoum, Apenten e Knapp (1996), para lipase de Pseudomonas fluorescens e Pastore, Costa e Koblitz (2003), utilizando lipases de Rhizopus sp.

As condições ótimas de atuação, bem como a estabilidade enzimática em bioprocessos, é um dos fatores de grande importância na escolha de enzimas. Em condições normais, a enzima apresenta uma estrutura nativa e ativa, mantida por um balanço de forças não covalentes (pontes de hidrogênio, forças iônicas, interações hidrofóbicas, forças de Van der Waals, etc.). Em elevadas temperaturas ou outras condições extremas, todas estas forças, com exceção das interações hidrofóbicas, diminuem e a enzima perde atividade por adquirir uma conformação mais desordenada. Na estrutura tridimensional nativa da enzima, o centro ativo consiste em diversos aminoácidos próximos entre si. Assim, o desdobramento da estrutura resulta na perda da atividade do sítio ativo da enzima (BORGSTRÖM; BROCKMAN, 1984).

Um outro fator que pode influenciar na inativação enzimática é o coeficiente de condutividade térmica do meio em que a enzima está exposta. Tendo isso em vista, experimentos foram realizados com temperaturas de 40,50 e $60^{\circ} \mathrm{C}$ utilizando sistema com maior eficiência de troca térmica (banho-maria) para avaliar a estabilidade da lipase. Durante esta avaliação o tratamento a $40{ }^{\circ} \mathrm{C}$ por 2 horas apresentou diminuição da atividade lipolítica em 15\%. No entanto, temperaturas de $50 \mathrm{e}$ $60^{\circ} \mathrm{C}$ afetaram significativamente a atividade lipolítica durante a primeira hora de exposição. A inativação da lipase durante 60,90 e 120 minutos para 50 e $60^{\circ} \mathrm{C}$ foram respectivamente 34 , 33 e $45 \%$. De um modo geral, a atividade enzimática diminui exponencialmente ao longo do tempo, obedecendo a um modelo de inativação de $1^{\mathrm{a}}$ ordem (Equação 1).

$-\frac{d A}{d t}=K_{d} \cdot A$

Integrando (Equação 2):

$A=A_{0} \cdot \exp \left(-K_{d} \cdot t\right)$

Aplicando a propriedade de logaritmo (Equação 3):

$\ln \frac{A}{A_{0}}=-K_{d} \cdot t$

Para determinar o tempo de meia vida da lipase nas condições estudadas, foi considerado que a concentração de enzima (A), após o tempo de exposição apresenta metade da concentração inicial $\left(A_{0}\right)$. A partir disso, pela Figura 2 determinou-se o valor de $k_{d}$ referente a cada condição. Os resultados encontrados durante a primeira hora de exposição se aproximaram bastante do modelo proposto (Equação 1), apresentando um bom ajuste para o modelo de primeira ordem. Em tempos superiores a 60 minutos, o efeito não foi significativo na perda da estabilidade da lipase. Os valores de $K_{d}$ encontrados foram 0,0015, 0,0051 e 0,0052 para as temperaturas de 40, 50 e $60^{\circ} \mathrm{C}$, respectivamente. Com isso tem-se que os tempos de meia vida foram respectivamente, 462,10, 135,91 e 133,30 minutos para 40,50 e $60^{\circ} \mathrm{C}$.
$\mathrm{Na}$ etapa de determinação da atividade enzimática em diferentes condições de $\mathrm{pH}$, foi observado que entre os $\mathrm{pHs}$ 5,0 e 7,0 aproximadamente $80 \%$ da atividade máxima encontrada foi mantida, sendo o pH 8,0 o melhor resultado encontrado (2,38 U.mL ${ }^{-1}$ e atividade específica de $\left.25,35 \mathrm{U}_{\mathrm{mg}}{ }^{-1}\right)$. Pequenas variações na atividade da enzima foram encontradas em $\mathrm{pHs}$ mais ácidos, porém em condições básicas observou-se maior sensibilidade da lipase. Perda de $80 \%$ de atividade da enzima foi verificada a pH 11,0. Os resultados estão mostrados na Figura 3. Desta forma, assim como os estudos realizados por Makhzoum, Apenten e Knapp (1996), pode-se verificar que a lipase de Pseudomonas cepacia é caracterizada como alcalina e análoga à lipase de Pseudomonas fluorescens. Resultados semelhantes foram encontrados por Sharma et al. (2002), após produção e purificação da lipase de Bacillus sp. Bradoo, Saxena e Gupta (1999) encontraram como pH ótimo para a lipase do Bacillus stearothermophilus valores entre 3,0 e 6,0.

\subsection{Diagrama de equilíbrio de fases}

Os diagramas de fases referentes aos PEG 1500, 4000 e 6000 para os pHs 6, 7 e 8 são mostrados respectivamente, nas Figuras 4, 5 e 6 . Albertsson (1971) menciona que quanto menor

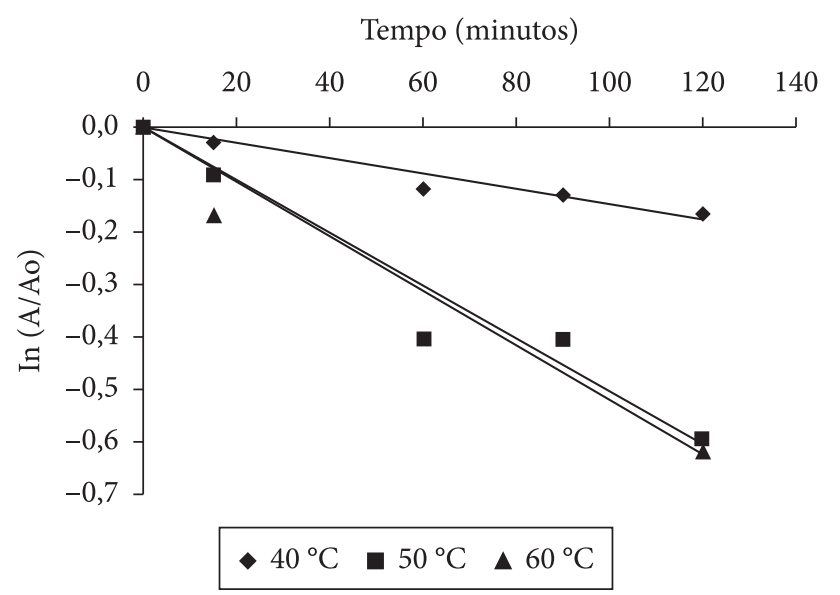

Figura 2. Linearização dos resultados da cinética de inativação enzimática em função do tempo de exposição da lipase.

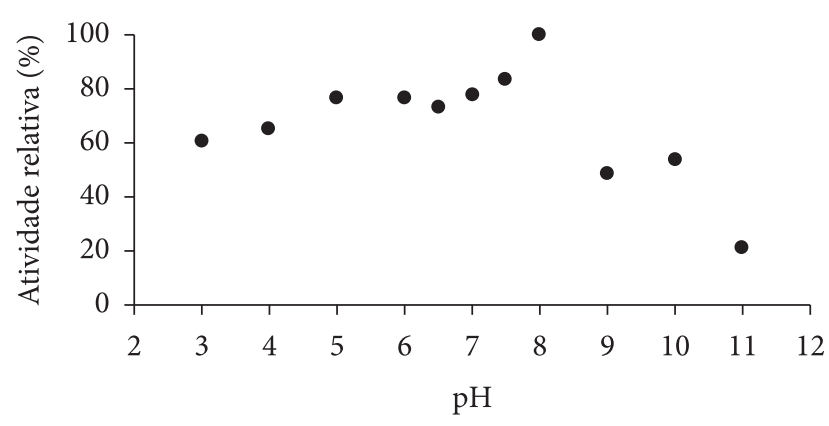

Figura 3. Atividade relativa de lipase produzida por Pseudomonas cepacia utilizando diferentes condições de $\mathrm{pH}$. 


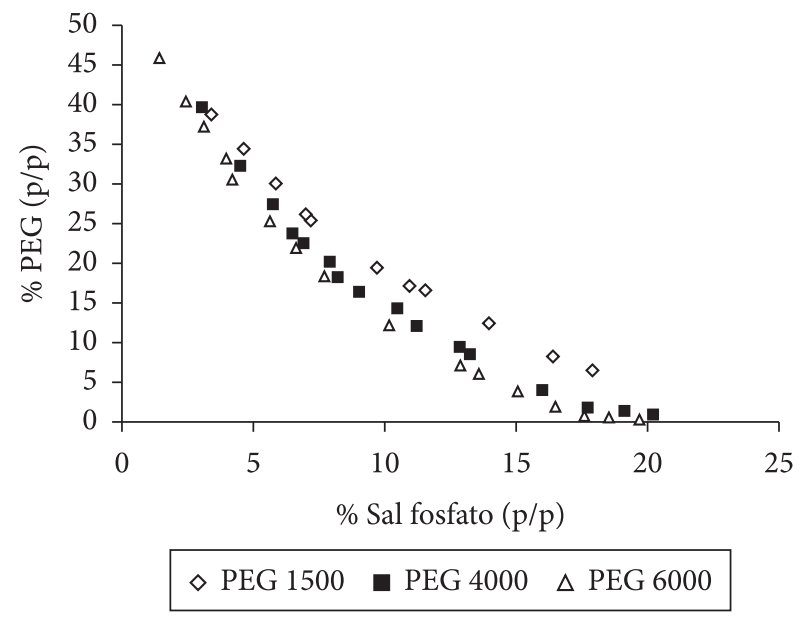

Figura 4. Diagrama de fases SBA PEG/Fosfato a pH 6.

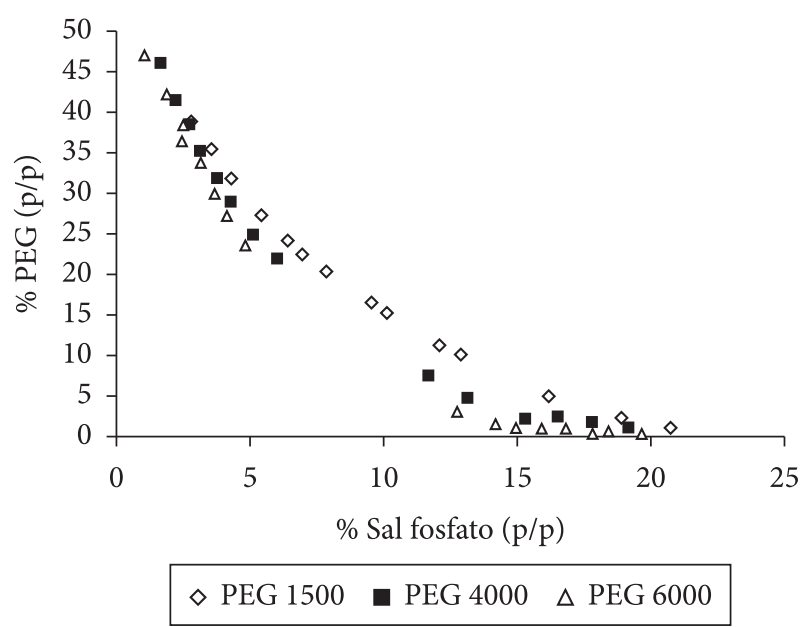

Figura 5. Diagrama de fases SBA PEG/Fosfato a pH 7.

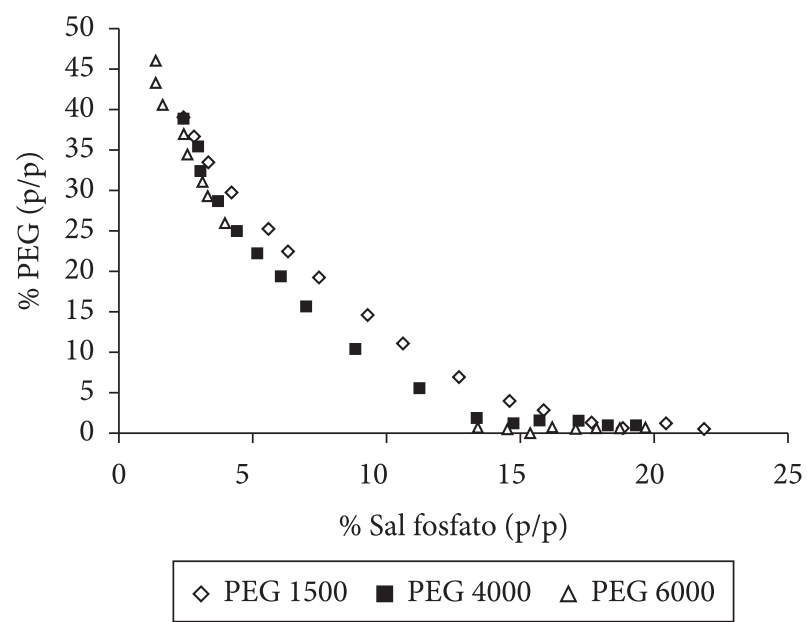

Figura 6. Diagrama de fases SBA PEG/Fosfato a pH 8. a massa molar do polímero, maior a concentração necessária para a formação de fases. Tendo em vista estas observações, no presente trabalho optou-se por realizar uma análise comparativa com PEG de diferentes pesos molares. Padilha et al. (2007) verificaram que o comportamento desses sistemas em diferentes valores de $\mathrm{pHs}$ apresentou um deslocamento não significativo das binodais. $\mathrm{O}$ que leva a concluir que a estabilidade destes sistemas frente às variações de $\mathrm{pH}$ e seu efeito sobre os SBAs não possuem características próprias (DIAMOND; HSU, 1992; FERREIRA et al., 2007).

\subsection{Linhas de amarração}

A partir da caracterização dos diagramas de fases, foram obtidas as linhas de amarração para posterior purificação das enzimas. As linhas de amarração para as diferentes condições de $\mathrm{pH}$ e massas molares de PEG são apresentadas na Tabela 1. A partir dos resultados, é possível verificar que não há variação significativa entre as composições das tie-lines para os diferentes pesos molares do $\mathrm{PEG}$ em relação à variação de $\mathrm{pH}$ do sistema. Existem muitos fatores que podem influenciar na partição de biomoléculas, dentre elas, a natureza química dos componentes formadores dos SBAs, $\mathrm{pH}$, temperatura, massa molar e concentração do polímero. Características como a estrutura, hidrofilicidade, peso molar, concentração e propriedades funcionais das moléculas também são fatores importantes que devem ser levados em consideração nos sistemas de partição (DA SILVA; LOH, 2006). Muitos pesquisadores têm observado bons resultados utilizando SBAs na partição de biomoléculas. Tais afirmações reforçam que o uso de SBAs é uma alternativa viável nas etapas preliminares de separação, principalmente no que se refere à minimização do tempo de operação e número de etapas de purificação de biomoléculas (ANDREWS; HUENUPI; ASENJO, 1999).

\section{Conclusões}

$\mathrm{Na}$ etapa de caracterização da enzima, os resultados apresentaram condições ótimas de atividade a $37^{\circ} \mathrm{C}$ e pH 8,0. Sua estabilidade a 50 e $60{ }^{\circ} \mathrm{C}$ foi afetada significativamente durante a primeira hora de exposição, seguindo um modelo de inativação de primeira ordem. A inativação da lipase durante 60,90 e 120 minutos a 50 e $60{ }^{\circ} \mathrm{C}$ foram respectivamente, 34 , 33 e $45 \%$. Os estudos de $\mathrm{pH}$ e temperatura são importantes na etapa de purificação da lipase, impedindo a perda de atividade pelo uso de condições que favoreçam sua inativação e redução da eficiência do método de purificação.

Para a caracterização dos sistemas bifásicos aquosos, em relação à massa molar do PEG, pode-se concluir que menores concentrações de soluções são necessárias para a formação de fases com PEG de maior massa molar. Foi observado que não houve um deslocamento significativo da binodal em relação aos diferentes $\mathrm{pH}$ s estudados, assim como sua pouca influência nas composições das linhas de amarração. Desta forma, o uso dos SBAs para purificação da lipase de Pseudomonas cepacia pode ser empregado evitando a desnaturação enzimática pela predominância de água no meio reacional. 
Padilha et al.

Tabela 1. Composição total do sistema com diferentes massas molares de PEG e pHs.

\begin{tabular}{|c|c|c|c|c|c|c|c|c|c|c|c|}
\hline & \multirow[t]{2}{*}{$\mathrm{pH}$} & \multirow[t]{2}{*}{ Tie-line } & \multicolumn{3}{|c|}{ Composição total do sistema $(\% \mathrm{~m} / \mathrm{m})$} & \multicolumn{3}{|c|}{ Composição da fase superior $(\% \mathrm{~m} / \mathrm{m})$} & \multicolumn{3}{|c|}{ Composição da fase inferior $(\% \mathrm{~m} / \mathrm{m})$} \\
\hline & & & PEG & SAL & $\mathrm{H}_{2} \mathrm{O}$ & PEG & SAL & $\mathrm{H}_{2} \mathrm{O}$ & PEG & SAL & $\mathrm{H}_{2} \mathrm{O}$ \\
\hline \multirow{7}{*}{$\begin{array}{l}\text { PEG } \\
1500\end{array}$} & \multirow[t]{2}{*}{6,0} & 1 & 17,8 & 12,9 & 69,3 & 31 & 5,6 & 63,4 & 5 & 19,5 & 75,5 \\
\hline & & 3 & 14,8 & 12,6 & 72,6 & 21 & 9,3 & 69,7 & 9 & 16 & 75 \\
\hline & \multirow[t]{2}{*}{7,0} & 1 & 19,3 & 12,3 & 68,4 & 37,5 & 3,1 & 59,4 & 1,5 & 21 & 77,5 \\
\hline & & 2 & 16,3 & 12,3 & 71,4 & 31 & 4,6 & 64,4 & 2 & 19,4 & 78,6 \\
\hline & \multirow[t]{3}{*}{8,0} & 1 & 17,9 & 12 & 70,1 & 35 & 3,2 & 64,8 & 0,7 & 20,5 & 78,8 \\
\hline & & 2 & 16,8 & 11 & 72,2 & 33 & 3,6 & 63,4 & 0,6 & 18,7 & 80,7 \\
\hline & & 3 & 15,8 & 10,6 & 73,6 & 29 & 4,4 & 66,6 & 1,9 & 16,8 & 81,3 \\
\hline \multirow{6}{*}{$\begin{array}{l}\text { PEG } \\
4000\end{array}$} & \multirow[t]{3}{*}{6,0} & 1 & 16,7 & 13,3 & 70 & 32 & 4,6 & 63,4 & 1,4 & 21,7 & 76,9 \\
\hline & & 2 & 11,4 & 13,8 & 74,8 & 21 & 7,9 & 71,1 & 1,5 & 19,5 & 79 \\
\hline & & 3 & 5,7 & 15,3 & 79 & 12,5 & 9 & 78,5 & 2 & 17,9 & 80,1 \\
\hline & \multirow[t]{3}{*}{8,0} & 1 & 19,5 & 11 & 69,5 & 19,5 & 2,2 & 78,3 & 2,4 & 37 & 60,6 \\
\hline & & 2 & 17,1 & 10,1 & 72,8 & 33 & 3 & 64 & 0,3 & 17 & 82,7 \\
\hline & & 3 & 14,7 & 9 & 76,3 & 28,5 & 4 & 67,5 & 1 & 14 & 85 \\
\hline \multirow{7}{*}{$\begin{array}{l}\text { PEG } \\
6000\end{array}$} & \multirow[t]{3}{*}{6,0} & 1 & 19 & 12,3 & 68,7 & 36 & 3,4 & 60,6 & 1,7 & 21 & 77,3 \\
\hline & & 2 & 13,1 & 12,6 & 74,3 & 25 & 6 & 69 & 1,3 & 18 & 80,7 \\
\hline & & 3 & 9,7 & 12,3 & 78 & 17 & 8,5 & 74,5 & 2,2 & 16 & 81,8 \\
\hline & \multirow[t]{3}{*}{7,0} & 1 & 21 & 11,6 & 67,4 & 38,5 & 2,3 & 59,2 & 4,2 & 21 & 74,8 \\
\hline & & 2 & 17,5 & 11,1 & 71,4 & 34 & 3,3 & 62,7 & 1,2 & 18,5 & 80,3 \\
\hline & & 3 & 14,6 & 10,8 & 74,6 & 29 & 4,2 & 66,8 & 0,3 & 17,5 & 82,2 \\
\hline & 8,0 & 1 & 23,7 & 10,5 & 65,8 & 43,6 & 1,4 & 55 & 20 & 3 & 77 \\
\hline
\end{tabular}

\section{Agradecimentos}

Os autores agradecem ao $\mathrm{CNPq}$ o suporte financeiro.

\section{Referências bibliográficas}

ALBERTSSON, P. A. Partition of cell particles and macromolecules. New York: Ed. John Wiley \& Sons, 1971.

ANDREWS, B. A.; HUENUPI, E.; ASENJO, J. A. Industrial prospects of aqueous two-phase processes. In: INTERNATIONAL CONFERENCE ON PARTITIONING IN AQUEOUS TWOPHASE SYSTEMS, 11., 1999, Alabama. Proceedings...

BADR, M. K.; CABEZAS, H. A thermodynamic model for the phase behavior of salt-polymer aqueous two-phase system. Fluid Phase Equilibria, v. 155, n. 17, p. 39-58, 1996.

BORGSTRÖM, B.; BROCKMAN, H. Lipases. New York: Ed. Elsevier, 1984.

BRADFORD, M. M. A rapid and sensitive method for the quantitation of microgram quantities of protein utilizing the principle of proteindye binding. Analytical Biochemistry, v. 72, p. 248-254, 1976.

BRADOO, S.; SAXENA, R. K.; GUPTA, R. Partitioning and resolution of mixture of two lipases from Bacillus stearothermophilus SB-1 in aqueous two-phase system. Process Biochemistry, v. 35, p. 57-62, 1999.
CABEZAS, H. Theory of phase formation in aqueous two-phases systems. Journal Chromatography B: Biomedical Applications, v. 680 , n. 17, p. 3-30, 1996.

CASTIGLIONI, G. L.; MONTE ALEGRE, R. Produção simultânea de lipase e bioemulsificante por Pseudomona cepacia. In: SIMPÓSIO LATINO AMERICANO DE CIÊNCIA DE ALIMENTOS, 6., 2007, Campinas - SP. Anais...

CASTRO, H. F.; ANDERSON, W. Fine chemicals by biotransformation using lipases. Química Nova, v.18, p. 544, 1995.

DA SILVA, L. H. M.; LOH, W. Sistemas aquosos bifásicos: fundamentos e aplicações para partição/purificação de proteínas. Química Nova, v. 29, n. 6, p. 1345-1351, 2006.

DIAMOND, A. D.; HSU, J. T. Aqueous two phase systems for biomolecule separation. Advances in Biochemical Engineering, V. 47, n. 135 , p. $89-135,1992$.

FERREIRA, G. B. et al. Partitioning Optimization of Proteins from Zea mays Malt in ATPS PEG 6000/ $\mathrm{CaCl}_{2}$ Brazilian Archives of Biology and Technology, v. 50, n. 3, p. 557-564, 2007.

HARRIS, J. M. Poly (ethylene glycol) chemistry: biochemical and biomedical applications. New York: Plenum Press, 1992.

HASAN, F.; SHAH, A. A.; HAMEED, A. Industrial applications of microbial lipases. Enzyme and Microbial Technology, v. 39, p. 235-251, 2006. 
JAEGER, K.; EGGERT, T. Lipases for biotechnology. Current Opinion in Biotechnology, v. 13, p. 390-397, 2002.

KIRK, O.; BORCHERT, T. V.; FUGLSANG, C. C. Industrial enzyme applications. Current Opinion in Biotechology, v. 13, p. 345-351, 2002.

KORDEL, M. et al. Extracellular lipase of Pseudomonas sp Strain ATCC 21808: purification, characterization, crystallization and preliminary X-ray diffraction data. Journal of Bacteriology, v. 177, n. 15, p. 4836-4841, 1991.

LIN, S. F. et al. Purification and partial characterization of an alkaline lipase from Pseudomonas pseudoalcaligenes F-111. Applied and Environmental Microbiology, v. 62, n. 3, p. 1093-1095, 1996.

MACEDO, G. A.; PARK, Y. K.; PASTORE, G. M. Partial purification and characterization of an extracellular lipase from a newly isolated strain of Geotrichum sp. Journal Brazilian Society for Microbiology, v. 28, p. 90-95, 1997.

MAKHZOUM, A.; APENTEN, R. K. O.; KNAPP, J. S. Purification and properties of lipase from Pseudomonas fluorescens strain 2D. International Dairy Journal, v. 6, n. 5, p. 459-472.

PADILHA, G. S. et al. Diagrama de fases para utilização em sistema bifásico aquoso com diferentes massas molares de PEG e pHs. In:
CONGRESSO BRASILEIRO DE POLÍMEROS, 9. 2007, Campina Grande. Anais...

PANDEY, A. et al. The realm of microbial lipases in biotechnology. Biotechnology Applied Biochemistry, v. 29, p. 119-131, 1999.

PASTORE, G. M.; COSTA, V. S. R.; KOBLITZ, M. G. B. Purificação parcial e caracterização bioquímica de lipase extracelular produzida por nova linhagem de Rhizopus sp. Ciência e Tecnologia de Alimentos, v. 23, n. 2, p. 135-140, 2003.

PENCREAC'H, G.; BARRATI, J. C. Hydrolysis of p-nitrophenyl palmitate in $\mathrm{n}$-heptane by the Pseudomonas cepacia lipase: a simple test for the determination of lipase activity in organic media. Enzyme and Microbial Technology, v. 18, p. 417-422, 1996.

PESSOA JR., A.; KILIKIAN, B.V. Purificação de produtos biotecnológicos. Barueri: Ed. Manole, 2005.

SHARMA, R. et al. Purification and characterisation of a thermostable alkaline lipase from a thermophilkic Bacillus sp. RSJ-1. Process Biochemistry, v. 37, p. 1075-1084, 2002.

ZUÑIGA, A. D. G. et al. Extração liquido-liquido usando sistemas aquosos bifásicos: uma revisão. Boletim da Sociedade Brasileira de Ciência e Tecnologia de Alimentos, v. 37, p. 89-102, 2003. 